\title{
DRUG UTILIZATION PATTERN IN GERIATRIC PATIENTS ATTENDING OUTPATIENT DEPARTMENT AT RURAL TERTIARY CARE HOSPITAL IN MAHARASHTRA
}

\author{
TUSHAR B NISHANDAR*, ANAND S KALE, HARSHAL N PISE
}

Department of Pharmacology, S.R.T.R. GMC, Ambajogai, Beed, Maharashtra, India. Email: nishandar9696@gmail.com

Received: 15 October 2016, Revised and Accepted: 01 November 2016

ABSTRACT

Objective: To observe a prescription pattern in elderly patients attending outpatient department (OPD) and evaluating prescriptions according to the World Health Organization (WHO) prescription indicators.

Methods: A cross-sectional observational study was conducted from July to September 2015. Patients of either gender, age 60 years or more, attending OPD in tertiary care hospital were included in the study. Prescriptions of medical practitioners were collected and evaluated for demographic data and the WHO drug prescribing indicators.

Results: A total of 600 patients were enrolled in the study. The majority of the patients were in the age group $60-69$ years (66.33\%) with male preponderance (61\%). The average number of drugs per prescription was 3.41 . Out of 2045 drugs prescribed, 1261 drugs (61.66\%) were prescribed by their generic name and 784 drugs (38.33\%) were prescribed by their brand name. 1700 drugs (83.12\%) prescribed were from the WHOs essential medicines list 2015 . Total encounters involving injectable usage were $0.15 \%$. Drugs acting on the cardiovascular system (21.12\%) were the most frequently prescribed, followed by nonsteroidal anti-inflammatory drugs (NSAIDs) (20\%). Ranitidine (16.62\%) is the most frequently prescribed drug.

Conclusions: In this study, drug prescription pattern was rational as per the WHO drug prescribing indicators. However, issues such as polypharmacy and inaccuracies of dose and duration were seen.

Keywords: Drug utilization study, Geriatric, Outpatient department, Rational use of medicines.

(C) 2017 The Authors. Published by Innovare Academic Sciences Pvt Ltd. This is an open access article under the CC BY license (http://creativecommons. org/licenses/by/4. 0/) DOI: http://dx.doi.org/10.22159/ajpcr.2017.v10i2.15683

\section{INTRODUCTION}

Aging generally increases an individual's risk of illness, and subsequently, increases use of medications, in spite of the great heterogeneity in health status and functional levels within the elderly population. Aging is associated with anatomical and physiological changes that affect how medications are metabolized by the body [1].

In developing countries like India, the proportion of elderly using at least one medication daily ranges from $85 \%$ to $90 \%$ [2-5]. This makes them more vulnerable for drug interactions and subsequently adverse drug reactions (ADRs). Geriatric patients have special problems regarding their health, social support, and economic security. Their health-care needs differ from the others.

Drug utilization research was defined by the World Health Organization (WHO) in 1977 as marketing, distribution, prescription, and use of drugs in society, with special emphasis on the resulting medical, social and economic consequences [6]. Drug utilization research is thus an essential part of pharmacoepidemiology as it describes the extent, nature, and determinants of drug exposure.

Despite being more vulnerable population, very few studies on drug utilization in geriatric patients have been carried out. Hence, we undertook this study with the broad aim of understanding the pattern of drug use in geriatric patients.

\section{METHODS}

This was an observational, cross-sectional study conducted in a tertiary care teaching hospital of rural Maharashtra, India. The study was conducted over a period of 4-month from July 2015 to October
2015 after approval of the Institutional Ethics Committee. A total of 600 patients enrolled in the study.

\section{Inclusion criteria}

Patients of either gender, age above 60 years attending OPD.

\section{Exclusion criteria}

1. Patients not willing to consent

2. Those with serious illness such as acute myocardial infarction, acute left ventricular failure, and diabetic ketoacidosis.

The diagnosis and line of treatment to be given were decided by the physician. No additional drugs or investigations were advised by us during the study period. Data of patients matching inclusion criteria were recorded. Before including in the study, the patients were explained about the research work. Written informed consent was taken from each patient before including him or her into the study.

Data collection was done by attending medical dispensary daily. Data was collected in predesigned pro forma for this study. Prescriptions were evaluated for demographic data, the WHO core drug prescription indicators such as an average number of drugs prescribed per prescription, percentage of drugs prescribed by generic name, percentage of drugs prescribed from essential drug list, percentage of antibiotics prescribed out of total drugs prescribed, and category wise distribution of drugs.

Statistical analysis was performed using Microsoft Office Excel ${ }^{\circledR} 2007$.

\section{RESULTS}

A total of 600 patients were enrolled in the study. The demographic data are shown in Table. 1 
Drugs were prescribed to 600 patients. The number of drugs ranged from 2 to 8 per person. In total, 135 cases (22.50\%) were found to have comorbid conditions. Hypertension is observed as the most common comorbid condition (76), followed by diabetes mellitus (36), Ischemic heart disease (16), chronic obstructive pulmonary diseases (9), and cerebrovascular accidents (3). A total number of 2045 drugs were prescribed, out of which $23(1.12 \%)$ were fixed dose combinations (FDCs). 2041 (99.80\%) patients were prescribed drugs by oral route, which was the most common route of drug administration.

The average number of drugs per prescription was 3.41. Out of 2045 total drugs prescribed, 1261 drugs $(61.66 \%)$ were prescribed by their generic name and 784 drugs (38.33\%) were prescribed by their brand name. $1700(83.12 \%)$ drugs prescribed were from the WHO-essential list of medicines (WHO-ELM). Total encounters having injectable formulations were $3(0.15 \%)$. The WHO Core Drug prescribing indicators are shown in Table 2 .

In our study, 432 (21.12\%) drugs acting on cardiovascular system were the most frequently prescribed drugs, followed by analgesics and NSAIDs $409(20 \%)$, drugs acting on gastrointestinal system 361 (17.65\%), antimicrobials 300 (14.66), Vitamins and minerals $262(12.81 \%)$. Distribution of various categories of drugs prescribed is depicted in Fig. 1.

In this study as depicted in Fig. 2, ranitidine was the most commonly prescribed (340) drug. It was followed by paracetamol (166), ibuprofen (152), multi vitamin B complex (133), and amlodipine (119)

\section{DISCUSSION}

Drugs are an integral part of the health care, and modern health care is impossible without the availability of necessary drugs. They not only save lives and promote health but also prevent epidemics and diseases too. Accessibility of medicines is the fundamental right of every person [7]. However, to bring optimal benefit, they should be safe, efficacious, cost-effective, and rational.

Drug utilization studies (DUS) are a tool for assessing the prescribing, dispensing, and distribution of drugs. The main aim of DUS is to facilitate rational use of medicines (RUM). Prescription monitoring studies provide a bridge between areas such as rational use of drugs, pharmacovigilance, evidence-based medicine, pharmacoeconomics, pharmacogenetics, and ecopharmacovigilance [8].

Treating the health problems of older patients presents a number of challenges, as these patients frequently have multiple health problems.

Table 1: Demographic data

\begin{tabular}{ll}
\hline Demographic parameters & Number of patients (\%) \\
\hline Age group (in years) & \\
$\quad 60-69$ & $398(66.33)$ \\
$70-79$ & $175(29.17)$ \\
$>80$ & $27(4.5)$ \\
Gender & \\
Male & $366(61)$ \\
Female & $234(39)$ \\
\hline
\end{tabular}

Table 2: WHO drug prescribing indicators

\begin{tabular}{ll}
\hline Average number of drugs per prescription & 3.41 \\
Drugs prescribed by generic name & $1261(61.66)$ \\
Drugs prescribed by brand name & $784(38.33)$ \\
Drugs from the WHO-ELM & $1700(83.12)$ \\
Drugs from NLEM 2015-16 & $1675(81.90)$ \\
Percentage encounters with injections & $03(0.15)$ \\
Percentage encounters with antibiotics & $201(33.5)$ \\
\hline
\end{tabular}

WHO-ELM: World Health Organization-essential list of medicines
As they are exposed to multiple drugs, thereby have increased incidence of drug-drug interactions and side effects of drug therapies. Multiple drug regimens and chronicity of diseases complicates this situation [1].

The study of prescribing patterns is a part of medical audit and seeks to monitor, evaluate if necessary, and suggest modifications in prescribing practices to make medical care rational and cost-effective [9]. Considering all these aspects, this study was undertaken to understand the drug use in geriatric patients attending OPD in tertiary care hospital.

In this study, male patients (61\%) outnumbered the female patients (39\%). A number of drugs prescribed per prescription was 3.41 is much lesser than that observed by Balaji et al. $(9.37 \pm 0.27)$ [10]. This difference can be attributed to the fact that later study was conducted in indoor patients in medical intensive care unit. Presently, polypharmacy is becoming more prevalent and increases chances of drug interactions, adverse drug events. It can be one of the most important reasons for noncompliance to medications. It also increases the health-care cost. It can affect the quality of life adversely.

Out of 2045 total drugs prescribed, 1261 (61.66\%) were prescribed by generic name. This is much more as compared to the findings of Kolhe et al. (22.64\%) [11] and that of Balaji et al. (53.26\%) [10] and that of Abraham et al. (12.06\%) [12], but still falls short of the WHO recommendation of $100 \%$. These findings clearly indicate that there is a need to encourage prescribing by generic names. Prescribing by generic name allows flexibility of stocking and dispensing various brands of a particular drug that are cheaper than and as effective as proprietary brands. This is the basis of use of drugs from essential drug list [13].

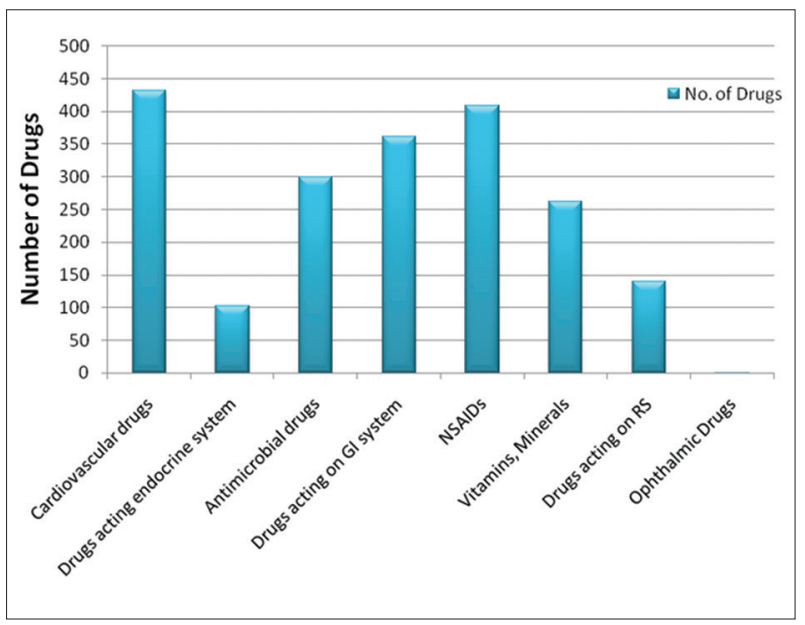

Fig. 1: Category of drugs

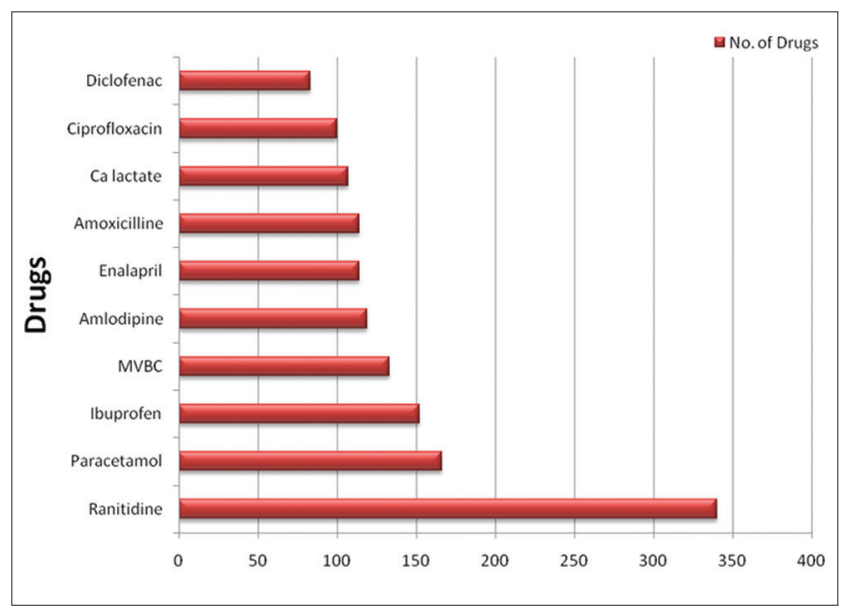

Fig. 2: Most frequently prescribed drugs 
In this study, 83.12\% drugs prescribed were from the WHO-ELM list which is more than that observed by Kolhe et al. (77.74\%), suggestive of rational drug use.

In this study, 2045 drugs were prescribed to a total of 600 patients for different diseases. Out of these drugs, $1.12 \%$ is FDCs which is much lesser than that reported by Kolhe et al. (18.35\%) [11]. FDCs increase the risk of drug interactions and ADRs. Moreover, they cause difficulty in titrating the dose of a particular drug as it is not possible to increase or decrease the dose of an individual ingredient alone. The use of FDCs can improve compliance with therapy by decreasing the number of formulations to be taken, but their risk/benefit ratio should be assessed before they are prescribed. However, considering vast variety FDCs available in India, the use of FDCs in our institution was found to be low, reflecting the RUM.

Similar to the findings of Kolhe et al. (23.36\%), drugs acting on cardiovascular system $(21.12 \%)$ were the most commonly prescribed drugs in our study [11]. A study of Abraham et al. found gastrointestinal agents (17.28\%) to be most commonly prescribed class of drugs [12]. In our study, most of the drugs were antihypertensives. This is supported by the fact that the prevalence of hypertension in the last six decades has increased from $2 \%$ to $25 \%$ among urban residents and from $2 \%$ to $15 \%$ among the rural residents in India [14]. Senescent changes in the cardiovascular system leading to decreased vascular compliance and baroreceptor sensitivity contribute to rising blood pressure. Increased vascular resistance is the hallmark of hypertension in elderly.

Followed by cardiovascular drugs, NSAIDs (20\%) were the next common drugs to be prescribed. The use of analgesics and NSAIDs in the elderly is due to complaints of body pains by this special population. This was followed by drugs acting on G.I. system (17.65\%), antimicrobials (14.66\%), vitamins and minerals (12.81\%).

In many prescriptions, dose and duration were not mentioned indicating inappropriate prescribing, which in geriatric patients has been linked to many ADRs, poor health, and drain of healthcare resources. Although it is difficult to contain the irrational drug prescribing practices, interventions in the forms of rational drug use workshop and problem-based training course in pharmacotherapy may prove useful in improving irrational drug prescribing practices $[15,16]$.

\section{CONCLUSIONS}

This study shows data of drug use in geriatric population in this tertiary care hospital. The positive findings were the prescription of a significant number of drugs from the WHO-ELM in generic names. There was lesser use of injections and FDCs. However, there was a trend toward polypharmacy and some inaccuracies in dose and duration of drugs were noted. More such studies are needed to substantiate these findings. Physicians need to be sensitized to this important public health issue.

\section{LIMITATIONS}

These data are from only one institute. Multicentric studies in this subject are needed, particularly over a period of a year, to avoid seasonal variation of disease pattern.

\section{REFERENCES}

1. Institute of Medicine (US) Committee on Pharmacokinetics and Drug Interactions in the Elderly. Pharmacokinetics and Drug Interactions in the Elderly and Special Issues in Elderly African-American Populations: Workshop Summary. Washington, DC: National Academies Press (US); 1997. Available from: https://www.ncbi.nlm.nih.gov/books/NBK45418/ pdf/Bookshelf_NBK45418.pdf. [Last assessed on 2016 Nov 17].

2. Mosegui GB, Rozenfeld S, Veras RP, Vianna CM. Quality assessment of drug use in the elderly. Rev Saude Publica 1999;33(5):437-44.

3. Bertoldi AD, Barros AJ, Hallal PC, Lima RC. Drug utilization in adults: Prevalence and individuals determinants. Rev Saude Publica 2004;38(2):228-38.

4. Ribeiro AQ, Rozenfeld S, Klein CH, César CC, Acurcio Fde A. Survey on medicine use by elderly retirees in Belo Horizonte, Southeastern Brazil. Rev Saude Publica 2008;42(4):724-32.

5. Rozenfeld S, Fonseca MJ, Acurcio FA. Drug utilization and polypharmacy among the elderly: A survey in Rio de Janeiro City, Brazil. Rev Panam Salud Publica 2008;23(1):34-43.

6. WHO. What is drug utilization research and why is it needed? In: Introduction to Drug Utilization Research. Ch. 1. Geneva: World Health Organization; 2003. p. 8-12. Available from: http://www.apps.who.int/ medicinedocs/pdf/s4876e/s4876e.pdf. [Last accessed on 2016 May 04].

7. Kar SS, Pradhan HS, Mohanta GP. Concept of essential medicines and rational use in public health. Indian $\mathrm{J}$ Community Med 2010;35(1):10-3.

8. Jain S, Upadhyaya P, Goyal J, Kumar A, Jain P, Seth V, et al. A systematic review of prescription pattern monitoring studies and their effectiveness in promoting rational use of medicines. Perspect Clin Res 2015;6(2):86-90.

9. Misra A, Misra A, Sarraf DP, Raunikar GP. Prescribing pattern of antimicrobials in the inpatients department of obstetrics and gynaecology at a tertiary care teaching hospital at Nepal. IJPBA 2013;4(5):893-8.

10. Balaji V, Aithal S, Geetha S, Swetha ES. Drug utilization pattern among geriatric patients admitted in medical intensive care unit of a tertiary care teaching hospital. Asian J Pharm Clin Res 2015;8(2):281-3.

11. Kolhe A, Kale AS, Padwal SL. Drug utilization study in geriatric patients at rural tertiary care hospital. Asian J Pharm Clin Res 2015;8(4):90-2.

12. Sam GK, Abraham F, Varughese G, Mathew JC, John PM. Drug utilization pattern among geriatric patients in a tertiary care teaching hospital. Asian J Pharm Clin Res 2015;8(6):191-4.

13. Adibe MO, Aguwa CN, Ukwe CV, Okonta JM, Udeogaranya PO. Outpatient utilization of antidiabetic drugs in the south eastern Nigeria. Int J Drug 2009;1(1):27-36.

14. Association of Physicians of India. Indian guidelines on hypertension (I.G.H.) - III. 2013. J Assoc Physicians India 2013;61 2 Suppl:6-36.

15. Pandey AA, Thakre SB, Bhatkule PR. Prescription analysis of pediatric outpatient practice in Nagpur city. Indian J Community Med 2010;35(1):70-3

16. Thomas M, Cherian AM, Mathai D. Measuring the impact of focused workshops on rational drug use. Trop Doct 1997;27(4):206-10. 